\title{
Evaluation of satellite precipitation products over Central Vietnam
}

\author{
Long Trinh-Tuan ${ }^{1,2^{*}}$ (D) Jun Matsumoto ${ }^{1,3}$, Thanh Ngo-Duc², Masato I. Nodzu ${ }^{1}$ and Tomoshige Inoue
}

\begin{abstract}
A comprehensive validation of three satellite precipitation datasets (SPDs), including (1) the Climate Prediction Center Morphing algorithm (CMORPH), (2) Global Satellite Mapping of Precipitation (GSMaP) Reanalysis, and (3) Tropical Rainfall Measuring Mission multi-satellite precipitation analysis (TRMM) 3B42, was conducted using the rain gauge-based Vietnam Gridded Precipitation dataset (VnGP) and rain gauge station data for Central Vietnam. The three SPDs were compared and evaluated for two contrasting topographic regions, i.e., the Vietnam Central Highlands (VCH) and the Vietnam Central Coast (VCC), during the rainy seasons from 2001 to 2010 at different spatial (grid and regional) and temporal (daily and monthly) scales. Widespread heavy rainfall (WHR) days caused by the Northeast Winter Monsoon (NM), the Inter-tropical Convergence Zone (ITCZ), and tropical cyclones (TCs) were also identified, and the accuracies of the SPDs in detecting heavy rainfall during the WHR days were evaluated. TRMM was shown to exhibit advantages over the other SPDs, regardless of the spatial and temporal scales. Although the CMORPH and GSMaP datasets appeared to correlate moderately well with the VnGP dataset and proved able to capture the spatial distribution of rainfall characteristics in the VCC, they significantly underestimated rainfall in the VCH. Regarding the capability to reproduce WHR events, the three SPDs exhibited better performance for TCs and the ITCZ than for the NM. TRMM exhibited the best performance among the three datasets, especially for rainfall thresholds ranging from 25 to $80 \mathrm{~mm}^{\text {day }}{ }^{-1}$. The GSMaP and CMORPH biases showed a clear dependence on elevation and zonal wind speed, indicating the need to improve correction methods.
\end{abstract}

Keywords: Satellite precipitation, Central Vietnam, Vietnam Central Highlands, Vietnam Central Coast, VnGP

\section{Introduction}

Rainfall is extremely important for human life, agriculture, and the global water cycle. In recent years, satellite precipitation products have developed rapidly and significantly, allowing satellite precipitation estimation to emerge as a valuable source of data and information, especially for developing countries that do not have an extensive ground observation network, such as Vietnam (Nguyen-Xuan et al. 2016). Satellite products can determine the distribution of precipitation with great spatial and temporal accuracy. They have also proven to be capable of providing data over areas inaccessible for ground weather radars or other in situ instruments. However,

\footnotetext{
*Correspondence: trinhtuanlong@gmail.com

'Department of Geography, Tokyo Metropolitan University, 1-1

Minami-Osawa, Hachioji-Shi, Tokyo 192-0397, Japan

${ }^{2}$ REMOSAT Laboratory, University of Science and Technology of Hanoi

(USTH), Vietnam Academy of Science and Technology (VAST), Hanoi, Vietnam Full list of author information is available at the end of the article
}

despite these enormous advantages, they exhibit poor performance for several reasons.

According to Dinku et al. (2008) and Gao and Liu (2013), two types of radiometric observations are popularly used to create satellite precipitation products, i.e., 1) infrared imagery, which has a high sampling frequency and produces precipitation estimates based on an indirect relationship with cloud-top temperature (consequently, the use of infrared algorithms is typically problematic for estimations involving warm orographic rain) and 2) microwave, including both passive imagery and microwave radar, which has fewer temporal sampling intervals but can provide precipitation estimates with higher accuracy due to the direct connection of the data with precipitation hydrometers. Owing to significant advancements in sensor technology and new methods for combining data sources, temporal and spatial resolutions and measurement accuracies have increased tremendously. Recently, the combination of microwave and infrared data has generated precipitation products with 
higher resolutions, allowing for the use of various emerging algorithms for hydrological purposes (Tapiador et al. 2012).

Many studies have been conducted to evaluate satellite precipitation products for different areas around the world. For example, Dinku et al. (2008, 2010) showed that some satellite precipitation products performed reasonably well on 10 day to monthly time scales, with a resolution of $2.5^{\circ}$ over the complex topography of East Africa. Thiemig et al. (2012) reported that the Climate Prediction Center Morphing (CMORPH) algorithm has the ability to replicate rainfall, even with the sparse ground data available in African river basins. Several studies reported that satellite observation does not sufficiently reproduce precipitation in high elevation areas such as the Tibetan Plateau (Yin et al. 2008), subtropical Andes (Hobouchian et al. 2017), river basins in Southeast Asia (Ngo-Duc et al. 2013), and African coastal areas (Toté et al. 2015). In addition, the performance of satellite precipitation products has been reported to vary among different regions. For instance, Vernimmen et al. (2012) and Jamandre and Narisma (2013) showed that CMORPH presented lower verification scores than the Tropical Rainfall Measuring Mission (TRMM) precipitation 3B42 Version 6 over Indonesia and the Philippines, respectively. In contrast, Shen et al. (2010) showed that CMORPH performed better for spatial and temporal patterns of precipitation over China compared to TRMM. These findings are also supported by Shige et al. (2013), who reported that the accuracy of the satellite estimations varies for different regions or countries as well as topographic profiles.

Very few studies to date have evaluated satellite precipitation products for Vietnam. Of most relevance, Ngo-Duc et al. (2013) evaluated the performance of the Global Satellite Mapping of Precipitation data (GSMaP MVK, Version 5) for North Central Vietnam and found large biases over the study area. The GSMaP quality was significantly improved with the implementation of a correction method using an artificial neural network. In recent decades, the National Hydro-Meteorological Service of Vietnam (NHMS, recently was renamed to Vietnam Meteorological Hydrological AdministrationVMHA) has recorded frequent severe floods that were mainly caused by heavy rainfall events in Central Vietnam. Previous studies have shown that heavy rainfall events in Central Vietnam are related to either tropical cyclones (TCs) (Nguyen-Thi et al. 2012), the Inter- tropical Convergence Zone (ITCZ), the Northeast Monsoon (NM), or sometimes a combination of two or more factors interacting with topography (Yokoi and Matsumoto 2008; Chen et al. 2012a, 2012b).

Accordingly, the aim of this study was to evaluate the performance of three satellite precipitation datasets (SPDs) for the Vietnam Central Highlands (VCH) from May to August (MJJA), and the Vietnam Central Coast (VCC) from September to December (SOND), where complex topography and contrasted rainfall seasonality are found (Nguyen-Le et al. 2015; Ngo-Thanh et al. 2017). Moreover, rivers in the VCC are fairly short and flow steeply, creating high probabilities of flooding during widespread heavy rainfall (WHR, defined in the next section) events. Therefore, WHRs caused by both TCs and ITCZ (hereafter termed TI) and by NM were specifically taken into consideration in this study to provide useful information for hydrological applications, such as water management and flood warning, in the VCC.

\section{Data and methods \\ SPDs}

The SPDs used in this study were (1) CMORPH Version 1.0, (2) Global Satellite Mapping of Precipitation (GSMaP) Reanalysis data Version 6, and (3) TRMM multi-satellite precipitation analysis 3B42 Version 7 (Table 1).

CMORPH is a precipitation dataset that uses microwave observation data from several satellites combined with geostationary infrared data (Joyce et al. 2004). In $\mathrm{CMORPH}$, the motion of cloud systems with propagation vectors was estimated using infrared data generated by geostationary satellites. Different bias correction methods were applied to the algorithm depending on its location, i.e., either over land or ocean. The satellite estimates were adjusted against the Climate Prediction Center $(\mathrm{CPC})$ daily rain gauge analysis for over-land data and merged with the Global Precipitation Climatology Program pentad data for over-ocean data (Xie et al. 2007, 2017). In the current study, data from CMORPH Version 1.0 (hereafter simply called CMORPH) with a three hourly bias correction at a spatial resolution of $0.25^{\circ}$ was used.

GSMaP integrates passive microwave with infrared data to provide precipitation estimates with high temporal (hourly) and spatial $\left(0.1^{\circ}\right)$ resolution. The standard product version GSMaP_MVK was produced based on a Kalman filter model that refined the precipitation rate

Table 1 Summary of the three SPDs used in this study

\begin{tabular}{lllll}
\hline Product & Provider & Spatial resolution (degree) & Temporal resolution $(\mathrm{h})$ & Temporal coverage \\
\hline CMORPH & NOAA-CPC & 0.25 & 3 & Since 1998 Jan. to 2015 Dec. \\
GSMaP & JAXA-EORC & 0.1 & 1 & Since 2000 Mar. to 2014 Feb. \\
TRMM & NASA/JAXA & 0.25 & 3 & Since 1998 Jan. to 2016 Dec. \\
\hline
\end{tabular}


propagated based on the atmospheric moving vector derived from two successive infrared images (Ushio et al. 2009). The reanalysis version of the GSMaP (GSMaP RNL) implemented the same GSMaP_MVK algorithms and used the Japanese 55 year reanalysis six hourly data (Kobayashi et al. 2015) as ancillary data to ensure the continuity and homogeneity of the dataset for the past period. The current study used GSMaP_RNL Version 6 (hereafter simply called GSMaP), since some noticeable improvements in the algorithms have been implemented since Version 5, such as an orographic rainfall correction method for warm rainfall in coastal areas (Yamamoto and Shige 2015).

Additionally, with combined estimations from multiple satellites based on both passive microwave and geostationary infrared data, TRMM was computed for realtime monitoring and post real-time research (referred to as 3B42). In the TRMM 3B42 algorithm, the calibration and combination of microwave precipitation estimates were followed by the generation of infrared precipitation estimates based on the calibrated microwave data. Infrared and microwave data were then combined before being rescaled on a monthly basis using the Global Precipitation Climatology Centre (GPCC) precipitation data (Huffman and Bolvin 2013). In the current study, data from TRMM 3B42 Version 7 (hereafter simply called TRMM) at 3 hour intervals were analyzed.

It should be noted that prior to this analysis, CMORPH and TRMM were already bias-adjusted using the CPC dataset (Xie et al. 2007) and the GPCC dataset (Schneider et al. 2014), respectively, while GSMaP was only based on satellite products. Thus, the monthly values from CMORPH and TRMM were expected to be closer to the observed rainfall values for the areas where rainfall stations are available.

\section{Gauge precipitation data}

To compare and evaluate the SPDs, the Vietnam Gridded Precipitation (VnGP) dataset (Nguyen-Xuan et al. 2016) and observational data obtained from rain gauge stations operated by the NHMS (Fig. 1 and Table 2) were used. VnGP is a daily gridded precipitation dataset produced from data collected by 481 rain gauges in Vietnam using the Spheremap interpolation method (Willmott et al. 1985). The VnGP dataset has two versions with spatial resolutions of $0.1^{\circ}$ and $0.25^{\circ}$, covering the period from 1980 to 2010 . In the present study, the VnGP dataset at the resolution of $0.25^{\circ}$ from 2001 to 2010 was used. In Vietnam, both daily rain gauge and VnGP data were collected and designated as $24 \mathrm{~h}$ rainfall amounts that were accumulated from 1200 UTC (1900 local time) on the previous day to 1200 UTC on the current day. For this reason, the daily-accumulated rainfall for the SPDs was computed for each grid on a

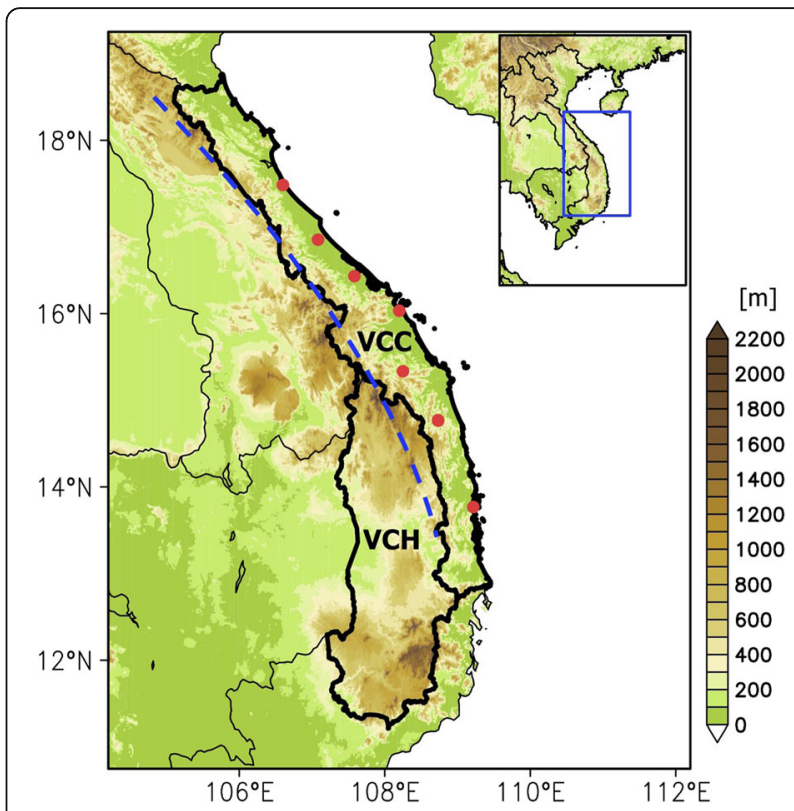

Fig. 1 Topography (shaded, $m$ ) of the VCC and the VCH (surrounded by thick-solid-black lines) and eastern part of the Indochina Peninsula.

The small blue box indicates the study region. The blue broken line indicates the Truong Son Mountains. The red points show rain gauge stations in the VCC and are listed in Table 2

particular day by summing the $1 \mathrm{~h}$ or $3 \mathrm{~h}$ rainfall data values for the same time span as that mentioned above before evaluations were processed.

To investigate the effects of monsoonal wind speed and elevation, both of which influence satellite precipitation estimations, the $925-\mathrm{hPa}$ zonal wind from ERA-Interim reanalysis data (Dee et al. 2011) with a spatial resolution of $0.25^{\circ}$ from ECMWF and the topography data from the Global 30 Arc-Second Elevation (GTOPO30) dataset were used.

\section{WHR days}

According to the NHMS, a WHR day over a region is defined as having occurred when the total rainfall recorded exceeds $50 \mathrm{~mm}$ day $^{-1}$ in at least half of the observed stations in that region. The synoptic features

Table 2 List of the seven meteorological stations in the VCC used in this study

\begin{tabular}{lllll}
\hline No. & Station & Lon $\left({ }^{\circ} \mathrm{E}\right)$ & Lat $\left({ }^{\circ} \mathrm{N}\right)$ & Altitude $(\mathrm{m})$ \\
\hline 1 & DongHoi & 106.60 & 17.48 & 7 \\
2 & DongHa & 107.08 & 16.85 & 7 \\
3 & Hue & 107.58 & 16.43 & 17 \\
4 & DaNang & 108.20 & 16.03 & 6 \\
5 & TraMy & 108.25 & 15.12 & 123 \\
6 & BaTo & 108.73 & 14.77 & 51 \\
7 & QuyNhon & 109.22 & 13.77 & 5 \\
\hline
\end{tabular}


causing WHRs were listed based on associated weather maps (NHMS 2017). It should be noted that the number of operational observed stations in the VCC might change over time and there was no precision given on the number of stations used for each WHR event in the NHMS reports. The identification of a WHR event by the NHMS was consequently based on the different lists of stations over time. Thus, the results could be changed if one station was added or removed. To ensure the consistency in identifying WHR days, the definition used in the present study is slightly different from that of the NHMS. In the VCC, daily rainfall data during 2001-2010 were collected at seven rain gauge stations (Fig. 1 and Table 2). A WHR in the VCC is defined, in the present study, as a day on which the rainfall recorded exceeded $50 \mathrm{~mm} \mathrm{day}^{-1}$ in at least four of the seven stations. Thus, the number of WHR days estimated here is slightly different from that reported by the NHMS. From 2001 to 2010, 154 WHR days caused by TI and 164 WHR days caused by NM (Table 3) were identified for the VCC in this study, whereas $163 \mathrm{TI}$ and $169 \mathrm{NM}$ WHR days were reported by the NHMS.

\section{Study area}

Central Vietnam, in the Indochina Peninsula region, is divided into two typical climatic sub-regions by the Truong Son Mountains (Fig. 1). In the east side, the VCC has a long coastal line that opens to the east, meaning the rainfall regime is mainly dominated by the influences of the TI and Northeast Winter Monsoon systems (Matsumoto 1997; Phan and Ngo-Duc 2009; Yen et al. 2011). Occasionally, WHR events occur owing to combinations of the above influences and their interactions with topography (Yokoi and Matsumoto 2008; Chen et al. 2012a, 2012b). Conversely, being located on the west side of the Truong Son Mountains, the VCH is influenced by the southwest summer monsoon and westward migrating convection systems during May to August (Phan and Ngo-Duc 2009; Yen et al. 2011; Takahashi 2013; Nguyen et al. 2014; Nguyen-Le et al. 2015). According to the VnGP dataset, rainfall during MJJA in the $\mathrm{VCH}$ accounts for approximately $50-70 \%$ of the annual rainfall (Fig. 2a). In contrast, due to the seasonal transition from the boreal summer to the winter monsoon, SOND rainfall contributes up to $60-80 \%$ of the annual precipitation in the VCC (Fig. 2b).

In addition, the difference at each grid point of the 10 year average rainfall between the highest and the lowest values among the three SPDs in MJJA (Fig. 3a) and SOND (Fig. 3b) was considered. There is a significant disparity in MJJA between the highest and the lowest grid values that exceeds $5 \mathrm{~mm} \mathrm{day}^{-1}$ in almost all grids of the $\mathrm{VCH}$. A point worth noting here is that a considerably large difference appears in MJJA rainfall for the west side of the high mountains in the northern region of the $\mathrm{VCH}$. However, the SOND rainfall disparity was up to $5 \mathrm{~mm} \mathrm{day}^{-1}$ in the VCC except for that in some grid boxes, which were observed in both the northern and southern regions of the VCC. This result demonstrates that the precipitation estimation over complex topographies such as those in the $\mathrm{VCH}$ and $\mathrm{VCC}$ are fairly different and thus challenging.

\section{Evaluation method}

The statistical indices used to compare the SPDs with VnGP for the two types of evaluation groups are presented separately.

To statistically compare the performance of the SPDs, GSMaP was remapped to a spatial resolution of $0.25^{\circ}$ to match those of TRMM, CMORPH, and VnGP. Then, the SPDs were evaluated with VnGP using the linear correlation coefficient (CORR), bias, and root mean square error (RMSE) ratio. The bias and RMSE ratio were estimated using the following formulae:

$$
\begin{aligned}
& \text { bias }=\frac{\sum_{i=1}^{n} S_{i}}{\sum_{i=1}^{n} V_{i}}-1, \\
& \text { RMSE }=\sqrt{\frac{\sum_{i=1}^{n}\left(S_{i}-V_{i}\right)^{2}}{n}} \\
& \text { RMSE ratio }=\frac{R M S E}{V},
\end{aligned}
$$

where $V_{i}$ is the precipitation value from $\mathrm{VnGP}, S_{i}$ is the precipitation value from the SPD, $n$ is the total number of data inputs, and $\bar{V}$ is the average value of $V_{i}$.

To evaluate the SPDs with rain gauge station data systematically, the SPDs were interpolated with values at the closest four grid points to the station locations. For evaluation of the SPD estimates at different precipitation thresholds on WHR days (Table 3), probability of detection (POD), false alarm ratio (FAR), and Heidke skill score (HSS), summarized in Table 4, were computed based on daily rainfall values with thresholds from 25 to $100 \mathrm{~mm} \mathrm{day}^{-1}$ at $5 \mathrm{~mm} \mathrm{day}^{-1}$ intervals at the seven stations in the VCC. The HSS is a measure of quality or skill in forecasts that compares the proportion of correct forecasts to a no-skill random forecast. A perfect forecast obtains a HSS of 1 , and a no skill forecast obtains a HSS of 0 . The POD and FAR provide complementary information on true alarms and false alarms (Toté et al. 2015). The value of POD ranges from 0 at the poor end to 1 at the good end. Conversely, the value of FAR ranges from 0 at the good end to 1 at the poor end. 
Table 3 WHR events during 2001-2010 detected in this study in the VCC and caused by TI and NM

\begin{tabular}{|c|c|c|c|c|c|}
\hline From & To & Duration (days) & From & To & Duration (days) \\
\hline \multicolumn{6}{|c|}{ Central Coast-TC and ITCZ (154 days) } \\
\hline Oct. 19, 2001 & Oct. 26, 2001 & 8 & Dec. 3, 2006 & Dec. 6, 2006 & 4 \\
\hline Nov. 12, 2001 & Nov. 15, 2001 & 4 & Oct. 1, 2007 & Oct. 5, 2007 & 5 \\
\hline Dec. 9, 2001 & Dec. 11, 2001 & 3 & Oct. 30, 2007 & Nov. 5, 2007 & 7 \\
\hline Sep. 18, 2002 & Sep. 25, 2002 & 8 & Nov. 10, 2007 & Nov. 13, 2007 & 4 \\
\hline Sep. 7, 2003 & Sep. 14, 2003 & 8 & Sep. 8, 2008 & Sep. 12, 2008 & 5 \\
\hline Sep. 24, 2003 & Sep. 26, 2003 & 3 & Sep. 28, 2008 & Oct. 1, 2008 & 4 \\
\hline Oct. 2, 2003 & Oct. 6, 2003 & 5 & Nov. 17, 2008 & Nov. 18, 2008 & 2 \\
\hline Oct. 14, 2003 & Oct. 20, 2003 & 7 & Sep. 3, 2009 & Sep. 9, 2009 & 7 \\
\hline Sep.17, 2004 & Sep. 19, 2004 & 3 & Sep. 22, 2009 & Sep. 26, 2009 & 5 \\
\hline Sep. 10, 2005 & Sep. 14, 2005 & 5 & Sep. 28, 2009 & Sep. 30, 2009 & 3 \\
\hline Sep. 18, 2005 & Sep. 20, 2005 & 3 & Oct. 15, 2009 & Oct. 23, 2009 & 9 \\
\hline Sep. 26, 2005 & Sep. 27, 2005 & 2 & Nov. 2, 2009 & Nov. 4, 2009 & 3 \\
\hline Oct. 7, 2005 & Oct. 13, 2005 & 7 & Oct. 14, 2010 & Oct. 19, 2010 & 6 \\
\hline Oct. 29, 2005 & Nov. 2, 2005 & 5 & Nov. 3, 2010 & Nov. 5, 2010 & 3 \\
\hline Sep. 23, 2006 & Sep. 27, 2006 & 5 & Nov. 13, 2010 & Nov. 17, 2010 & 5 \\
\hline Sep. 29, 2006 & Oct. 4, 2006 & 6 & & & \\
\hline \multicolumn{6}{|c|}{ Central Coast—Northeast Monsoon (164 days) } \\
\hline Oct. 4, 2001 & Oct. 5, 2001 & 2 & Nov. 24, 2005 & Nov. 26, 2005 & 3 \\
\hline Dec. 13, 2001 & Dec. 15, 2001 & 3 & Nov. 30, 2005 & Dec. 8, 2005 & 9 \\
\hline Oct. 6, 2002 & Oct. 7, 2002 & 2 & Dec. 11, 2005 & Dec. 21, 2005 & 11 \\
\hline Oct. 14, 2002 & Oct. 16, 2002 & 3 & Dec. 10, 2006 & Dec. 11, 2006 & 2 \\
\hline Oct. 24, 2002 & Oct. 26, 2002 & 3 & Oct. 13, 2007 & Oct. 18, 2007 & 6 \\
\hline Nov. 1, 2002 & Nov. 4, 2002 & 4 & Nov. 16, 2007 & Nov. 20, 2007 & 5 \\
\hline Nov. 6, 2002 & Nov. 12, 2002 & 7 & Nov. 22, 2007 & Nov. 24, 2007 & 3 \\
\hline Nov. 10, 2003 & Nov. 14, 2003 & 5 & Dec. 4, 2007 & Dec. 7, 2007 & 4 \\
\hline Nov. 23, 2003 & Nov. 25, 2003 & 3 & Oct. 10, 2008 & Oct. 13, 2008 & 4 \\
\hline Dec. 8, 2003 & Dec. 11, 2003 & 4 & Oct. 16, 2008 & Oct. 18, 2008 & 3 \\
\hline Sep. 9, 2004 & Sep. 13, 2004 & 5 & Oct. 23, 2008 & Oct. 25, 2008 & 3 \\
\hline Oct. 2, 2004 & Oct. 4, 2004 & 3 & Oct. 27, 2008 & Oct. 30, 2008 & 4 \\
\hline Oct. 23, 2004 & Oct. 24, 2004 & 2 & Nov. 3, 2008 & Nov. 6, 2008 & 4 \\
\hline Oct. 27, 2004 & Oct. 29, 2004 & 3 & Nov. 23, 2008 & Nov. 27, 2008 & 5 \\
\hline Nov. 15, 2004 & Nov. 18, 2004 & 4 & Dec. 5, 2008 & Dec. 7, 2008 & 3 \\
\hline Nov. 23, 2004 & Nov. 28, 2004 & 6 & Sep. 29, 2010 & Oct. 5, 2010 & 7 \\
\hline Dec. 1, 2004 & Dec. 2, 2004 & 2 & Oct. 27, 2010 & Oct. 28, 2010 & 2 \\
\hline Oct. 18, 2005 & Oct. 20, 2005 & 3 & Oct. 30, 2010 & Nov. 2, 2010 & 4 \\
\hline Oct. 22, 2005 & Oct. 26, 2005 & 5 & Nov. 6, 2010 & Nov. 10, 2010 & 5 \\
\hline Nov. 16, 2005 & Nov. 20, 2005 & 5 & Nov. 28, 2010 & Nov. 30, 2010 & 3 \\
\hline
\end{tabular}

\section{Results}

\section{Overall performance} Central Highlands (VCH)

Figure 4 shows the scatter plots for the $\mathrm{VCH}$ regional mean daily and monthly precipitation data from the SPDs in comparison with VnGP during MJJA of 2001-2010. On both the daily and monthly scales, TRMM shows good agreement with the VnGP data while GSMaP and $\mathrm{CMORPH}$ significantly underestimate rainfall over the $\mathrm{VCH}$ region. On the daily scale, the CORR values for CMORPH and GSMaP are 0.66 and 0.60 , respectively. Moreover, the performances of the SPDs are better on the 


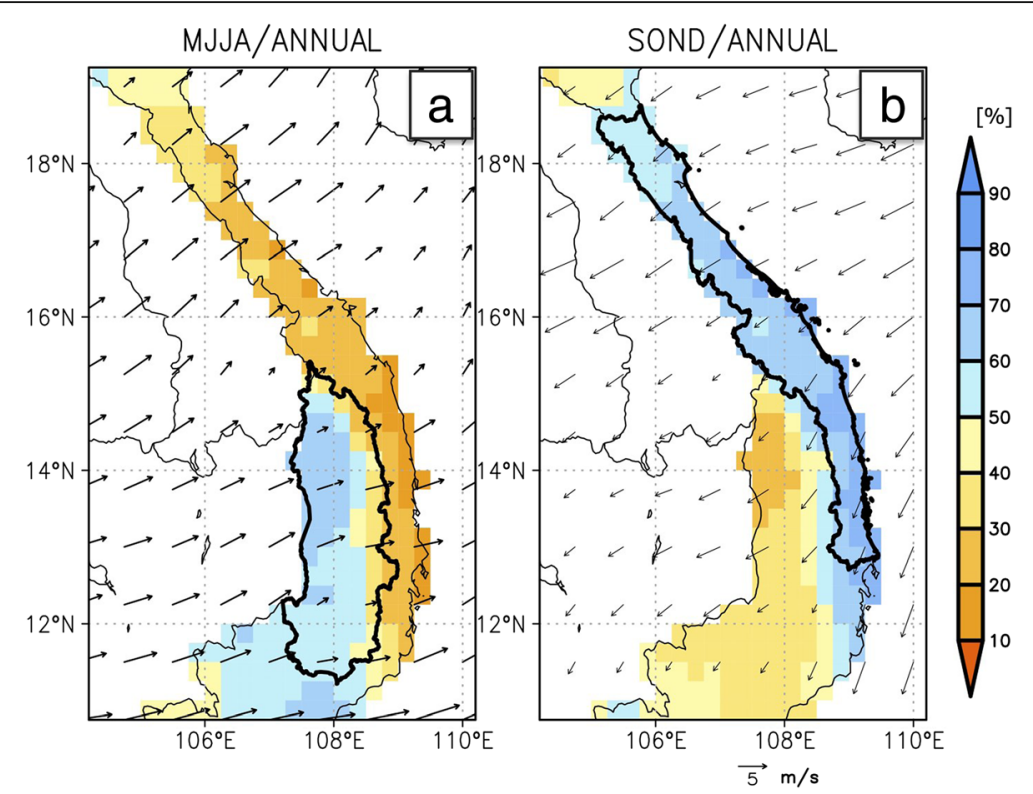

Fig. 2 Spatial patterns of a MJJA and $\mathbf{b}$ SOND total rainfall contribution in percentage to annual rainfall over Central Vietnam averaged for 20012010, derived from the VnGP data. Vectors show horizontal wind fields at $925 \mathrm{hPa}$ averaged for the corresponding months and years, derived from ERA-Interim reanalysis data. The VCH and the VCC are surrounded by black thick lines in a MJJA and $\mathbf{b}$ SOND patterns, respectively

monthly scale with high CORRs of $0.93,0.71$, and 0.69 for TRMM, CMORPH, and GSMaP, respectively.

The spatial distribution of seasonal MJJA precipitation in the VCH is shown in Fig. 5. The VnGP dataset shows two local rainfall maxima in the west of the $\mathrm{VCH}$ with values up to $15 \mathrm{~mm} \mathrm{day}^{-1}$. Additionally, the decrease in precipitation amounts from the west to the east is also recognized. TRMM generally represents the VnGP patterns well, while CMORPH and GSMaP do not. Both CMORPH and GSMaP underestimate the precipitation amount compared to VnGP, especially in the southeastern and northern regions of the $\mathrm{VCH}$ in which high mountains are found. Relatively low CORR values are obtained with CMORPH and GSMaP compared to that with TRMM over the same region.

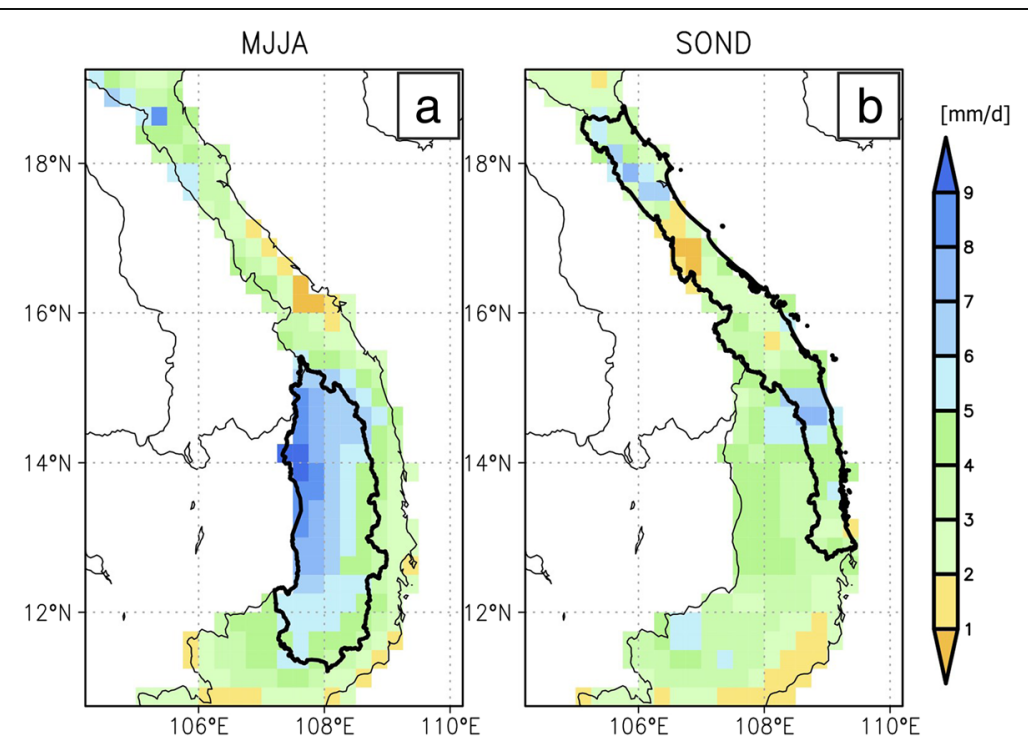

Fig. 3 Spatial patterns of SPDs' rainfall difference between maximum and minimum values among the three SPDs at each grid point in Central Vietnam, averaged for a MJJA and $\mathbf{b}$ SOND in 2001-2010. The VCH and the VCC are surrounded by black thick lines in a MJJA and $\mathbf{b}$ SOND patterns, respectively 
Table 4 Summary of the statistics, POD, FAR and HSS, used in this study. They are computed from counts (letters $a-d$ ) in a $2 \times 2$ contingency table ( $N=1078$ in TI case, $N=1148$ in NM case). a SPD rainfall > threshold, VnGP rainfall > threshold; $b$ SPD rainfall > threshold, VnGP rainfall $\leq$ threshold; $\mathrm{C}$ SPD rainfall $\leq$ threshold, VnGP rainfall $>$ threshold; and $d$ SPD rainfall $\leq$ threshold, VnGP rainfall $\leq$ threshold

\begin{tabular}{llll}
\hline Name & Formula & Perfect score & Worst score \\
\hline POD & $a /(a+c)$ & 1 & 0 \\
FAR & $b /(a+b)$ & 0 & 1 \\
HSS & $2(a d-b c) /((a+c)(c+d)+(a+b)(b+d))$ & 1 & $-\infty$ \\
\hline
\end{tabular}

Figure 6 shows the comparison between the three SPDs and VnGP over the VCH for MJJA in 20012010. It can be seen that TRMM has a relatively small bias with VnGP with the 25th and 75th percentiles at -0.05 and $0.20 \mathrm{~mm} \mathrm{day}^{-1}$, respectively. On the monthly scale, TRMM performs well, showing a CORR median value of 0.80 and an RMSE ratio median value of 0.29 . The median values of CORR and RMSE ratio for GSMaP are 0.60 and 0.52 , while those for CMORPH are 0.58 and 0.77 , respectively. However, on the daily scale, the three SPDs do not differ significantly in terms of RMSE ratio and CORR. The median values of CORR and RMSE ratio range from 0.51 to 0.54 , and from 1.23 to 1.45 , respectively. Higher estimation accuracy is observed for the monthly scale than for the daily scale. In terms of statistical indicators, TRMM shows the best performance on both monthly and daily scales (except for daily RMSE ratio), while CMORPH shows the highest errors on the monthly scale.

\section{Central Coastal area (VCC)}

Comparisons between the SPDs and VnGP for daily and monthly precipitation were processed on a regional scale for the VCC, as shown in the scatter plot in Fig. 7. On the daily scale, good agreements with the VnGP data are observed for all three SPDs on the grid scale with high CORRs of 0.86 for TRMM and CMORPH and 0.81 for GSMaP. The degree of reliability increases as the temporal scale transitions from daily to monthly scales with a CORR value higher than 0.84 .

Figure 8 displays the spatial patterns of SOND rainfall, of rainfall differences and correlations between each of the three SPDs and VnGP. The VnGP patterns show an area of heavy local seasonal mean precipitation located from around 15 to $17^{\circ} \mathrm{N}$ in SOND, in which the daily rainfall exceeds $15 \mathrm{~mm} \mathrm{day}^{-1}$. In general, the SPDs present relatively similar precipitation patterns to those of VnGP. However, they significantly underestimate precipitation throughout the whole VCC (Fig. 8 middle panel), except in some locations in the northern and
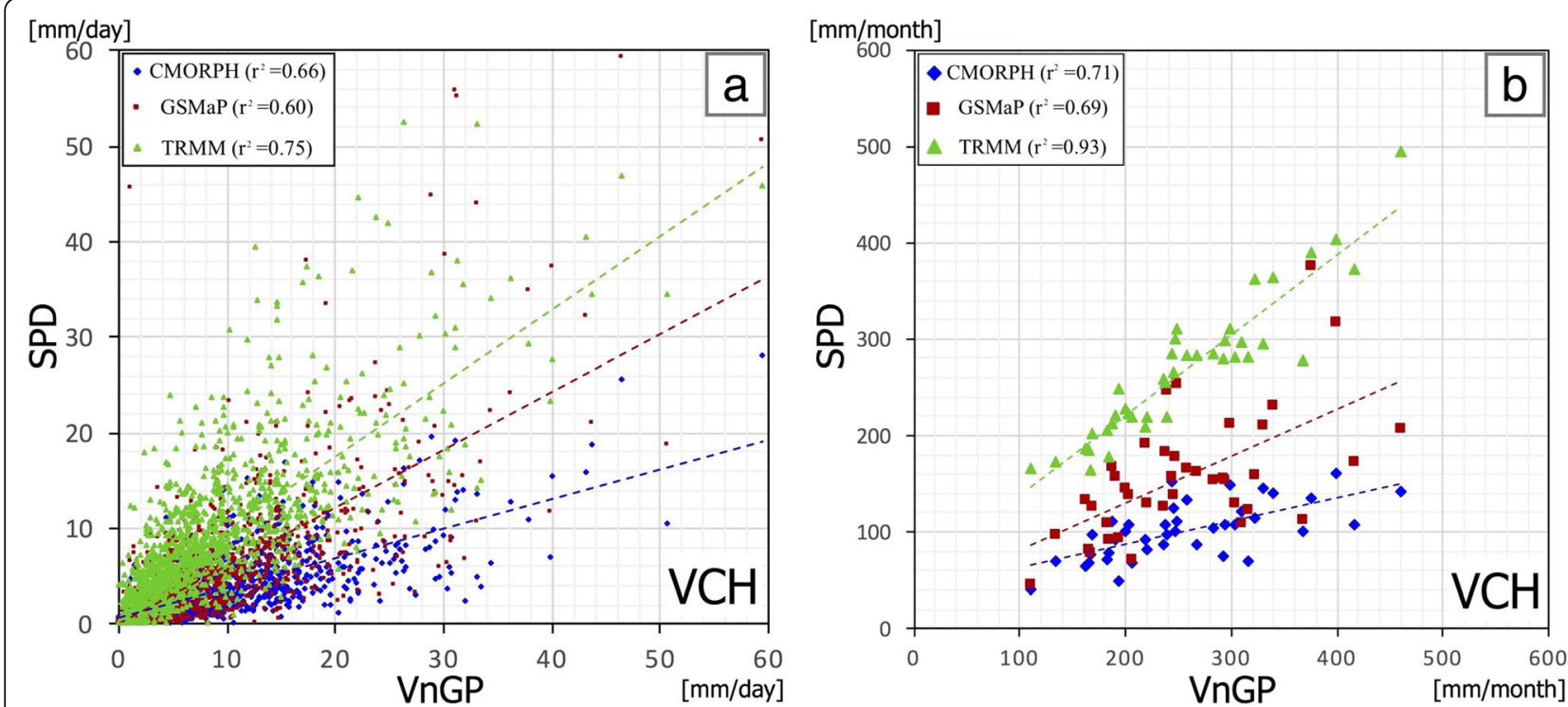

Fig. 4 Scatter plots of VnGP and SPDs (CMORPH, GSMaP, and TRMM) regional mean rainfall over the VCH for MJJA in 2001-2010, for a daily and b monthly values. Sample numbers are $N=1230$ and 40 for each scatter plot of daily and monthly values, respectively. Correlation coefficients between each SPD and VnGP are also displayed 


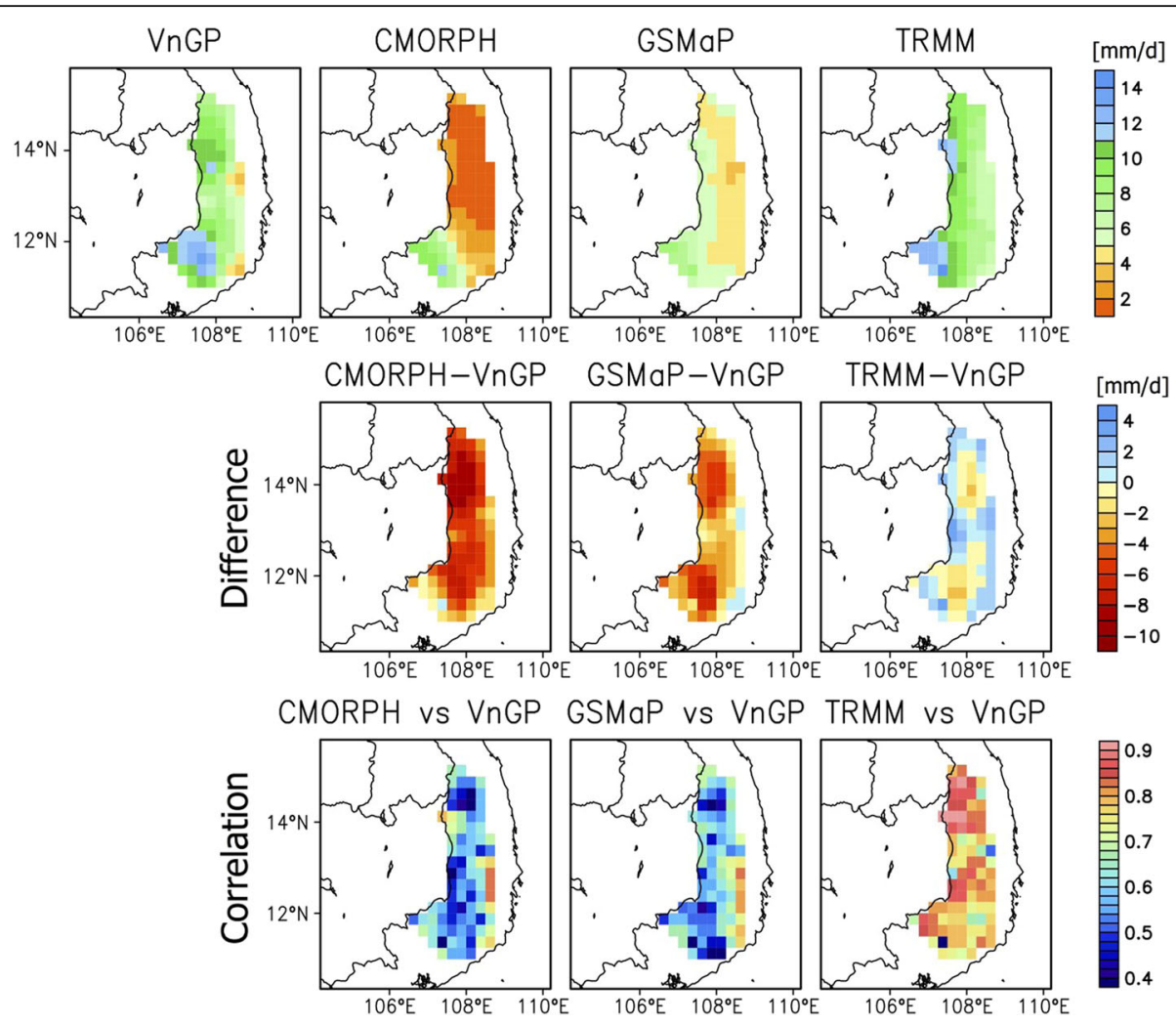

Fig. 5 Upper panels (from left): spatial patterns of 4 month (MJJA), 10 year (2001-2010) averaged daily rainfall for VnGP, and three SPDs (CMORPH, GSMaP and TRMM) over the VCH. Middle panels (from left): spatial patterns of 4 month (MJJA), 10 year (2001-2010) averaged daily rainfall difference between each SPD and VnGP. Lower panels (from left): CORR grid-point values between each SPD and VnGP for monthly rainfall in MJJA during 2001-2010

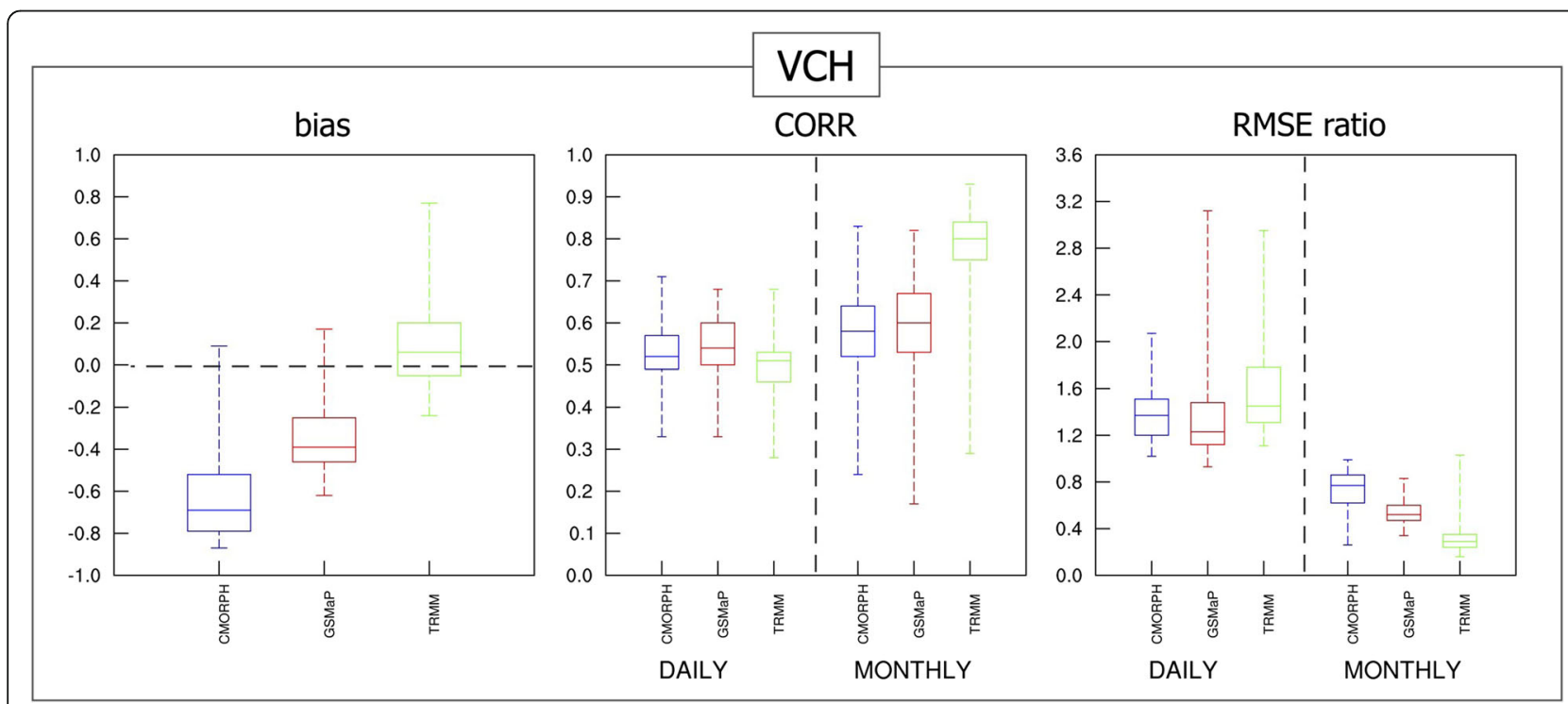

Fig. 6 Boxplots for bias, CORR, and RMSE ratio for 88 grid point values over the VCH for comparison of three SPDs (CMORPH, GSMaP, and TRMM) with monthly VnGP rainfall, for MJJA in 2001-2010. Boxplots of CORR and RMSE ratio values are shown also for daily rainfall. Sample numbers are $N=1230$ for each bias value, $N=1230$ for each CORR or RMSE ratio value for daily rainfall, and $N=40$ for each CORR or RMSE ratio value for monthly rainfall 

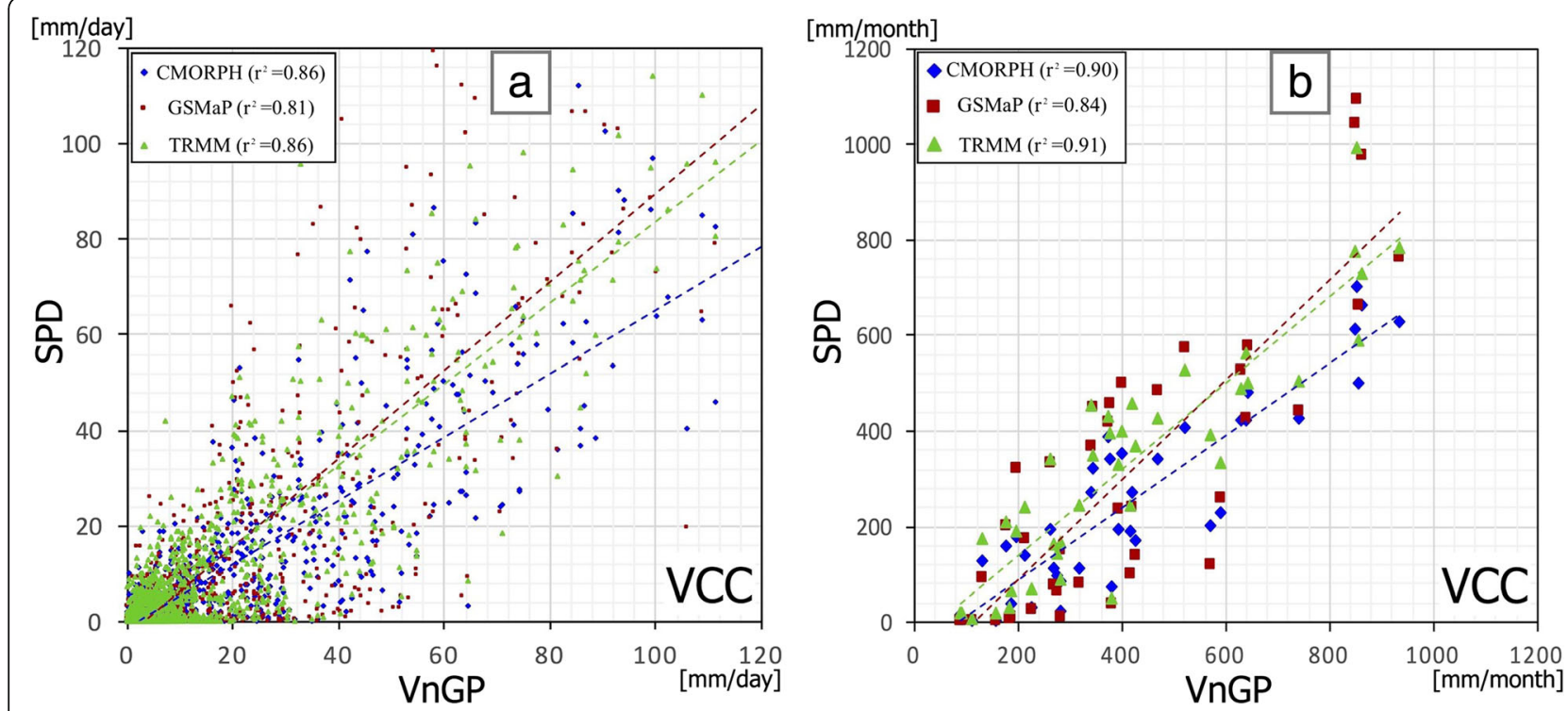

Fig. 7 a, b Same as Fig. 4, except for SOND rainfall over the VCC. Sample numbers are $N=1220$ for each scatter plot of daily values and $N=40$ for monthly values
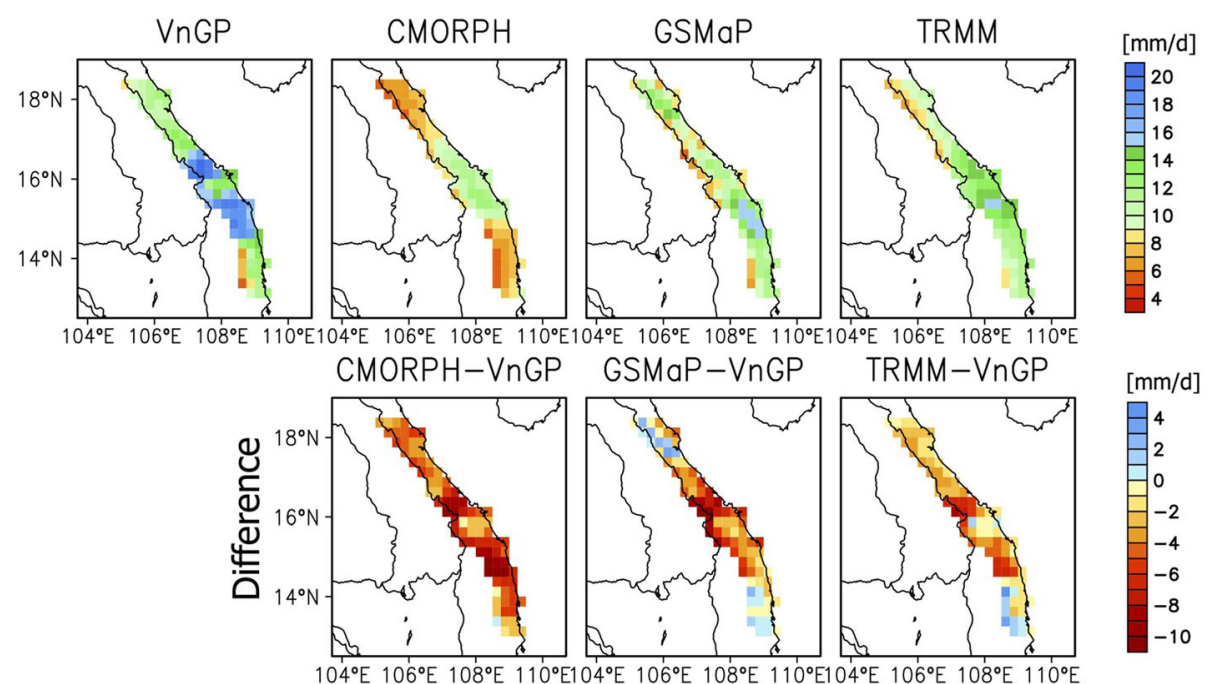

$104^{\circ} \mathrm{E} 106^{\circ} \mathrm{E} 108^{\circ} \mathrm{E} 110^{\circ} \mathrm{E} 104^{\circ} \mathrm{E} 106^{\circ} \mathrm{E} 108^{\circ} \mathrm{E} 110^{\circ} \mathrm{E} 104^{\circ} \mathrm{E} 106^{\circ} \mathrm{E} 108^{\circ} \mathrm{E} 110^{\circ} \mathrm{E}$ CMORPH Vs VnGP
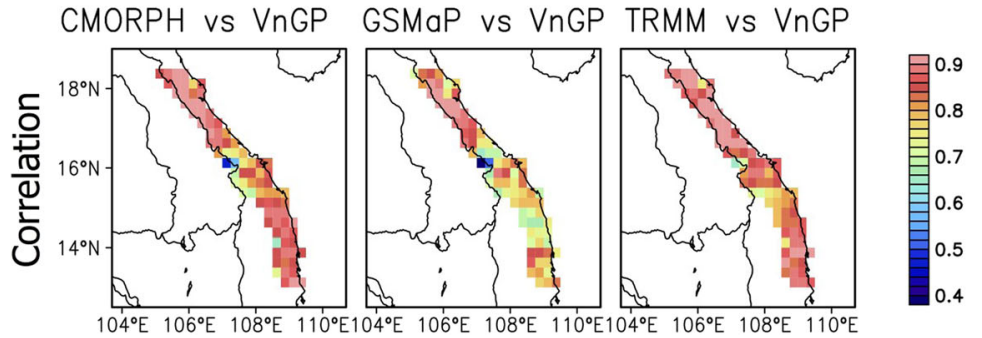

Fig. 8 Same as Fig. 5, except for SOND rainfall over the VCC 


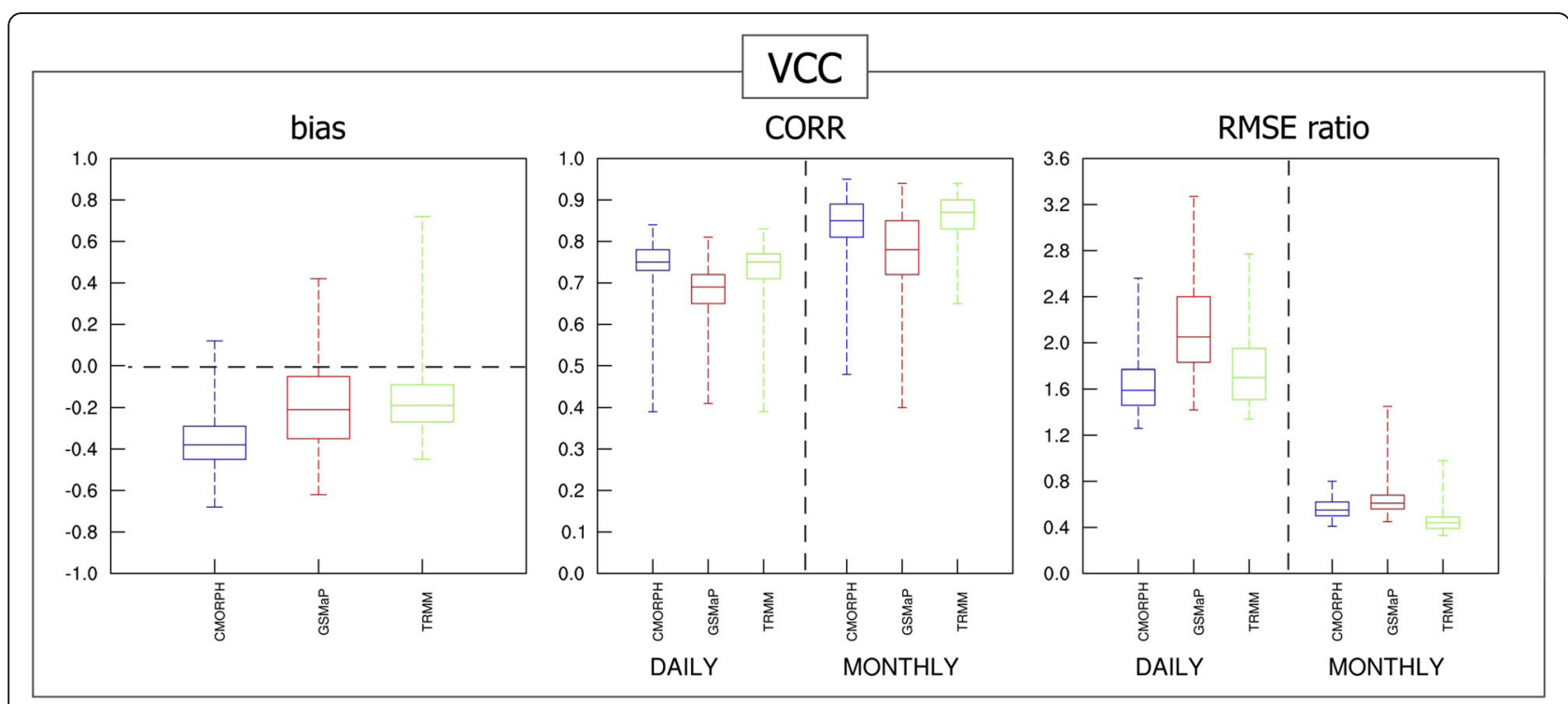

Fig. 9 Same as Fig. 6, except for SOND rainfall over the VCC for 85 grid point values. Sample numbers are $N=1220$ for each bias value, $N=1,220$ for each CORR or RMSE ratio value for daily rainfall, and $N=40$ for each CORR or RMSE ratio value for monthly rainfall

southern parts of the region, where GSMaP or TRMM slightly overestimate rainfall.

Figure 9 shows the comparison between the three SPDs and VnGP over the VCC for SOND in 2001-2010. The three SPDs show rather high median CORR values (from approximately $0.78-0.87$ ) on the monthly scale. TRMM and CMORPH show similar performances on the grid scale, which makes them better than GSMaP in terms of CORR. It is worth noting that there is a significant improvement for GSMaP Version 6 compared to Version 5 for the observed precipitation in the VCC. Ngo-Duc et al. (2013) reported that GSMaP Version 5 performed poorly and that its rainfall results even had negative correlations with the gauged data from several stations in the VCC. Conversely, in the current study, GSMaP Version 6 shows reasonably positive correlations for every grid point of the coastal region. This improvement was also observed by Yamamoto and Shige (2015), who reported that the algorithm of GSMaP Version 6 provided improved rainfall estimations over the coastal area compared to those of the previous version.

\section{Performance for capturing rainfall thresholds}

Figure 10 shows the RMSE ratio values computed for each SPD for each threshold of regional averaged daily rainfall. Generally, the RMSE ratios decrease with increasing precipitation intensity for all three SPDs in both the VCC and VCH. For rainfall of less than $10 \mathrm{~mm}$ day $^{-1}$, the RMSE ratios of the three SPDs are relatively high, i.e., higher than 0.75 and 1.0 for the $\mathrm{VCH}$ and VCC, respectively. In the VCC, the RMSE ratio values for CMORPH and TRMM when precipitation intensities

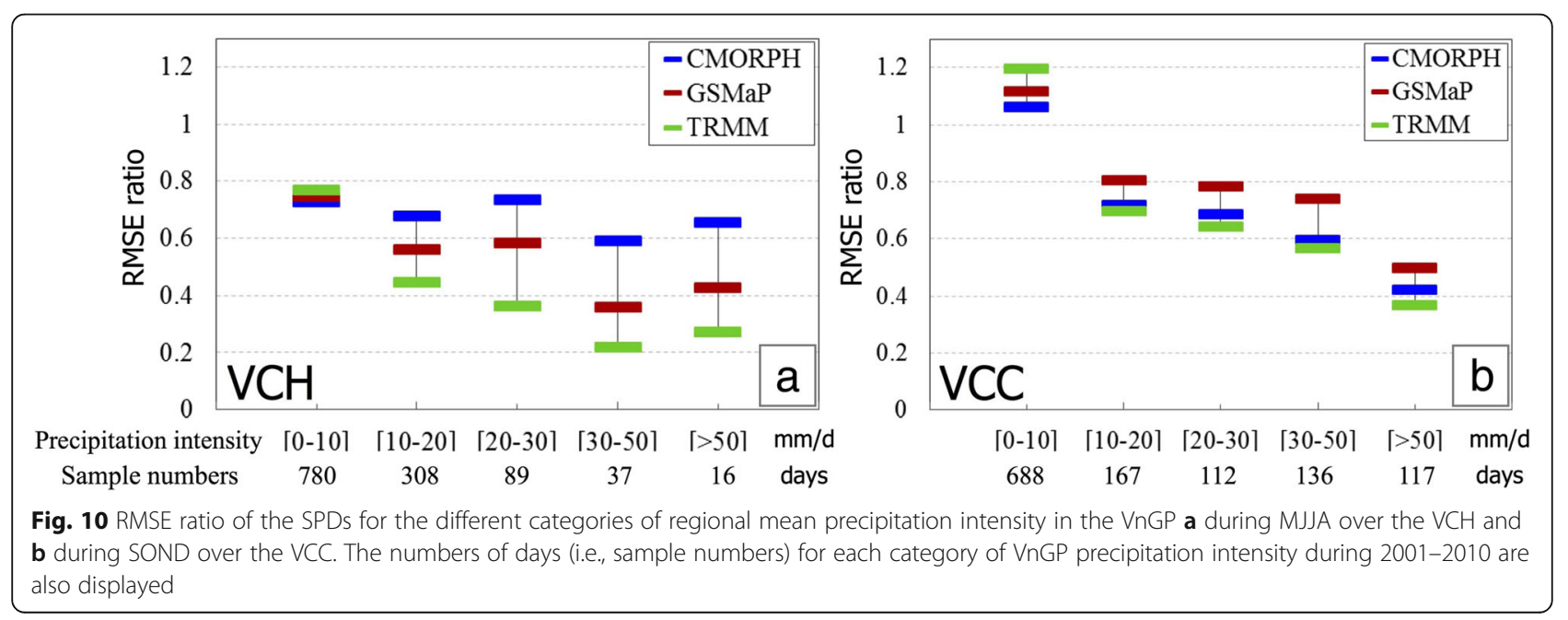


are greater than $50 \mathrm{~mm} \mathrm{day}^{-1}$ are close to 0.4 and less than 0.4 , respectively. In the $\mathrm{VCH}$, the performances of TRMM for precipitation thresholds of more than 10 $\mathrm{mm} \mathrm{day}^{-1}$ are better than those of GSMaP, which in turn outperforms CMORPH. Conversely, in the VCC, TRMM and CMORPH show relatively similar performances and both also perform better than GSMaP for rainfalls of more than $10 \mathrm{~mm} \mathrm{day}^{-1}$. The better quality of TRMM and CMORPH compared to that of GSMaP can be partly explained by the fact that TRMM and CMORPH are bias-corrected by rain gauge-based datasets, which take into account station data from the VCC (Xie et al. 2007; Schneider et al. 2014). It is worth noting that, for rainfalls of less than $10 \mathrm{~mm} \mathrm{day}^{-1}$, the performance of TRMM is slightly poorer than those of GSMaP and $\mathrm{CMORPH}$, as evidenced by its higher RMSE ratios for both the VCC and $\mathrm{VCH}$. This result is in agreement with Figs. 4 and 7 where the daily TRMM values are very different from that of VnGP in the low-intensity category.

Figure 10 also shows the number of days for each threshold of the VnGP precipitation intensity during 2001-2010. Over the $\mathrm{VCH}$ during the 10 year MJJA period, only $4.3 \%$ of the days (i.e. 53 days) show regional averaged rainfalls of more than $30 \mathrm{~mm} \mathrm{day}^{-1}$, while this number decreases to $1.3 \%$ (i.e., only 16 days) for the threshold of more than $50 \mathrm{~mm} \mathrm{day}^{-1}$. Over the VCC, during the 10 year SOND period, $20.7 \%$ and $9.6 \%$ of the days (i.e., 253 days and 117 days, respectively) show regional averaged rainfalls of more than $30 \mathrm{~mm} \mathrm{day}^{-1}$ and more than $50 \mathrm{~mm} \mathrm{day}^{-1}$, respectively. Consequently, the number of heavy rainfall days over the VCC is significantly higher than that over the $\mathrm{VCH}$.

\section{Discussions}

Our results demonstrate that TRMM exhibits the best performance for both the $\mathrm{VCH}$ and $\mathrm{VCC}$ in terms of the monthly time scale and that it exhibits not only the highest CORR values, but also the lowest bias and lowest RMSE ratios. This could be due to the fact that TRMM uses multi-sensor passive microwave data combined with infrared and microwave radar data. Additionally, this product uses the GPCC dataset for bias corrections at the monthly scale. CMORPH performs better in the VCC than in the VCH. Hobouchian et al. (2017) reported that CMORPH has a tendency to provide substandard estimations in high-elevation areas. In addition, CMORPH was calibrated using the CPC daily gauge analysis data, which does not use any data from stations in the VCH (Xie et al. 2007). Moreover, CMORPH performs fairly well in the VCC, where there is a higher station density. The underestimations by GSMaP and CMORPH in the VCH could be attributed to the fact that the satellite rainfall algorithms underestimate for orographic convection with relatively low echo-top heights (Shige and Kummerow 2016).

\section{Ability of SPDs to detect heavy rainfall on WHR days}

As mentioned above, the number of days having regional averaged rainfalls of more than $50 \mathrm{~mm}^{\text {day }}{ }^{-1}$ in the VCC is significantly higher than that in the $\mathrm{VCH}$. During 2001-2010, 154 WHR days caused by TI and 164 WHR days caused by NM (Table 3) were identified based on the data from seven rain gauge stations in the VCC (Fig. 1, Table 2). The relationships between rainfall thresholds ranging from 25 to $100 \mathrm{~mm} \mathrm{day}^{-1}$ and the POD, FAR, and HSS values of the SPD daily rainfall estimates with rain gauge observations at the seven stations on the WHR days are plotted in Fig. 11. Generally, the POD decreases while FAR increases with increasing rainfall thresholds, except for the FAR values for CMORPH in the NM cases. The HSS values for CMORPH and TRMM range from 0.48 to 0.65 and reach the highest value when the rainfall amounts are around 50 to $70 \mathrm{~mm} \mathrm{day}^{-1}$. The POD and HSS values for CMORPH decrease when daily rainfall exceeds $75 \mathrm{~mm}$. In contrast, regarding the NM cases, the POD and FAR of the three SPDs roughly decrease from 0.5 to 0.3 and increase 0.1 to 0.35 , respectively, when the rainfall thresholds are increased from 25 to $100 \mathrm{~mm} \mathrm{day}^{-1}$. These results indicate that CMORPH and TRMM, which use bias correction, are able to detect heavy rainfall effectively on the TI WHR days. The ability of CMORPH to effectively detect heavy rainfall noticeably decreases when daily rainfall exceeds $75 \mathrm{~mm}$.

Compared to the NM cases, heavy rainfall in the TI cases is detected more accurately. This can be explained by the fact that the deep cloud convections that form in the TI cases are captured more easily than those in the Northeast Monsoon cloud system. In both the TI and NM WHR cases, TRMM shows good performance for detecting heavy rainfall. This result is consistent with the findings of Tang et al. (2015), who reported that the improvements in Version 7 of TRMM decrease random errors compared to Version 6. Conversely, GSMaP exhibits lower performance for detecting heavy rainfall on the WHR days in the VCC compared to CMORPH and TRMM. It should be noted that GSMaP uses Kalman filtering, which might be subject to an induced offset for the extreme precipitation by averaging the forward and backward propagated passive microwave estimates (Ushio et al. 2009). However, compared to its previous version, GSMaP shows a better performance in the coastal areas.

\section{Potential factors influencing satellite precipitation estimations}

Many satellite rainfall algorithms assume that heavy rainfall is associated with high echo-top heights (Shige 

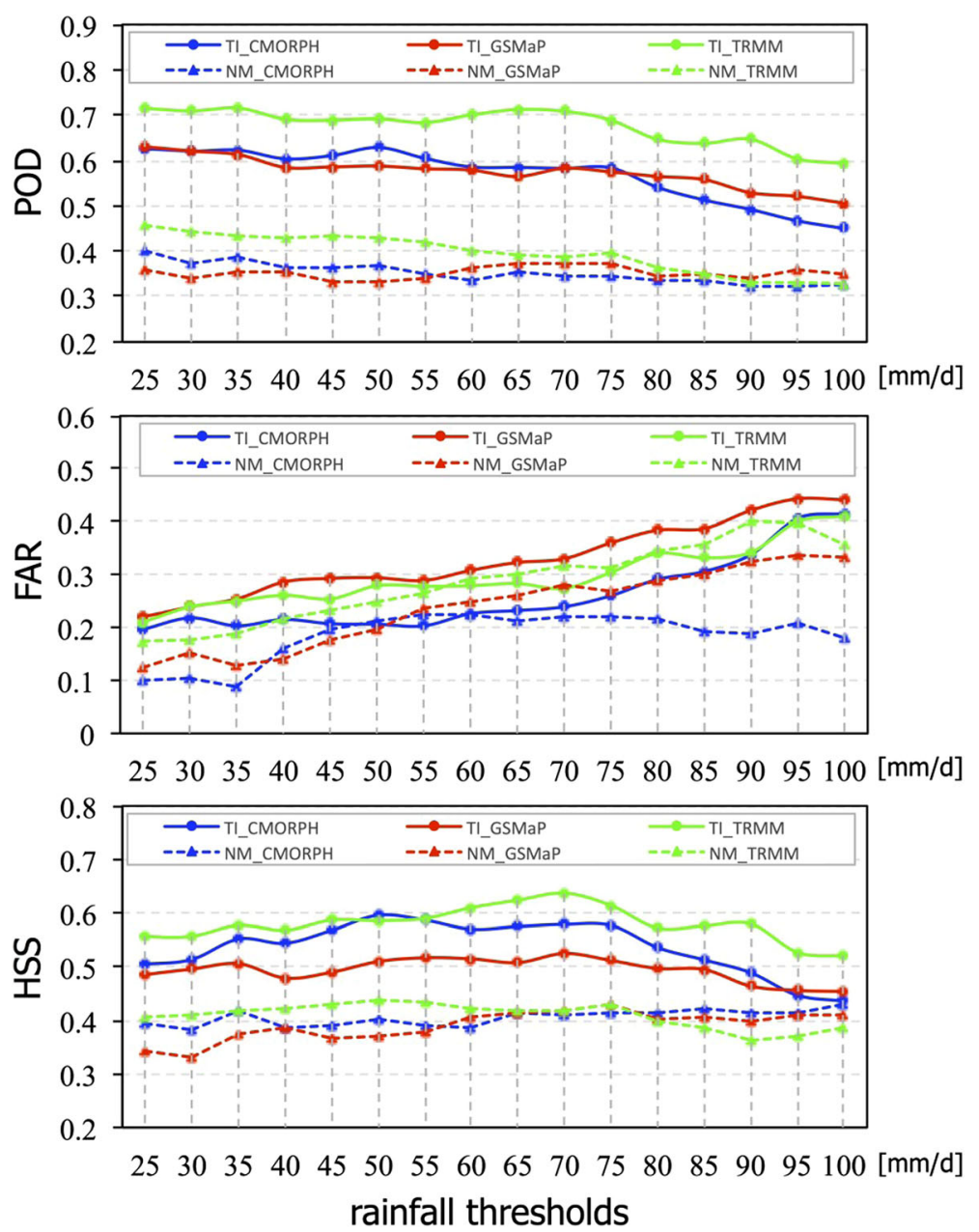

Fig. 11 The relations between rainfall thresholds and the POD, FAR, and HSS values of SPDs' daily rainfall estimates with rain gauge observations at the seven stations on the WHR TI and NM days listed in Table 3

and Kummerow 2016). Thus, this can lead to conspicuous underestimation with conventional satellite products in the area where heavy orographic rainfall is frequently associated with shallow convection systems such as the coastal mountain ranges of the Asian monsoon region, including Central Vietnam (Kubota et al. 2009, Shiget et al. 2013, Shige and Kummerow 2016). As orographic convection is driven by two factors, i.e., differential heating between air over elevated terrain and adjacent plain and forced ascent by strong wind approaching the mountain, wind speed consequently plays an important role in controlling the convection (Nugent et al. 2014) and thus has influence on the performance of satellite rainfall products. Ngo-Duc et al. (2013) examined the dependence of the performance of a satellite product (GSMaP MVK Version 5) on the elevation and on the 925-hPa zonal wind speed over a river basin in Central Vietnam. They reported that the satellite product exhibited large negative rainfall biases with high zonal wind speed in the winter monsoon. Moreover, the biases tended to increase as the elevation decreased. Consequently, in this study, the SPDs were examined in relation to zonal wind speed and elevation, both of which contribute to shallow orographic rain systems in the $\mathrm{VCH}$ and $\mathrm{VCC}$.

Figure 12 shows the scatter diagrams for $\Delta P$, which is defined as the monthly regional mean of precipitation difference between the SPDs and VnGP, and the monthly zonal wind speed ( $U$ component) of ERA-Interim at $925 \mathrm{hPa}$ from May to August in the $\mathrm{VCH}$ and September to December in the VCC. It is clear that, in the $\mathrm{VCH}$, the $U$ component is always positive, which means the summer monsoon was active during MJJA (Fig. 12a). Conversely, the negative values of the $U$ component reveal that the VCC was dominated by NM in SOND (except for September) (Fig. 12b). As a result, on the windward side of the Truong Son Mountains, the stronger the westerly wind, the larger the underestimates 

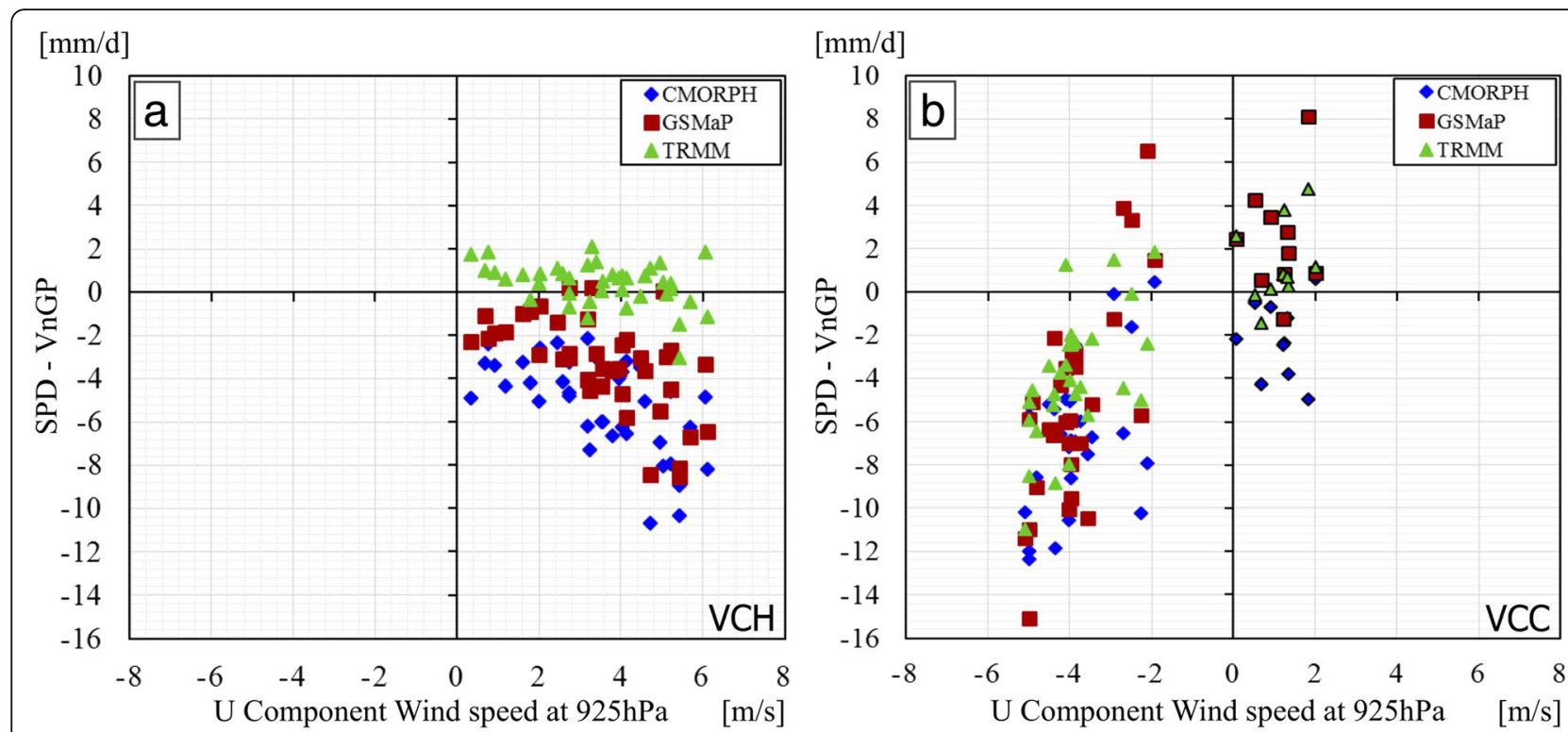

Fig. 12 Scatter plots between the zonal wind component at $925 \mathrm{hPa}$ (abscissa, unit $\mathrm{m} \mathrm{s}^{-1}$ ) in the ERA interim and rainfall difference $\Delta P$ (SPDs rainfall minus the VnGP rainfall; ordinate, unit $\mathrm{mm}$ day $^{-1}$ ) averaged for each region and each month during MJJA in the VCH (a) and SOND in the VCC (b) from 2001 to 2010. N=40 for each plot, black-bordered marks show the values in September

for the $\mathrm{VCH}$, and the stronger the easterly wind, the larger the underestimates for the VCC except for September. The absolute values of $\Delta P(|\Delta P|)$ tend to increase as wind speed (absolute value of the $U$ component) increases. In the $\mathrm{VCH}$, it can be seen that the slopes for CMORPH and GSMaP are relatively large, which means their rainfall estimations are strongly dependent on zonal wind speed. Furthermore, TRMM does not show any significant dependence on zonal wind speed. The majority of the precipitation in the $\mathrm{VCH}$

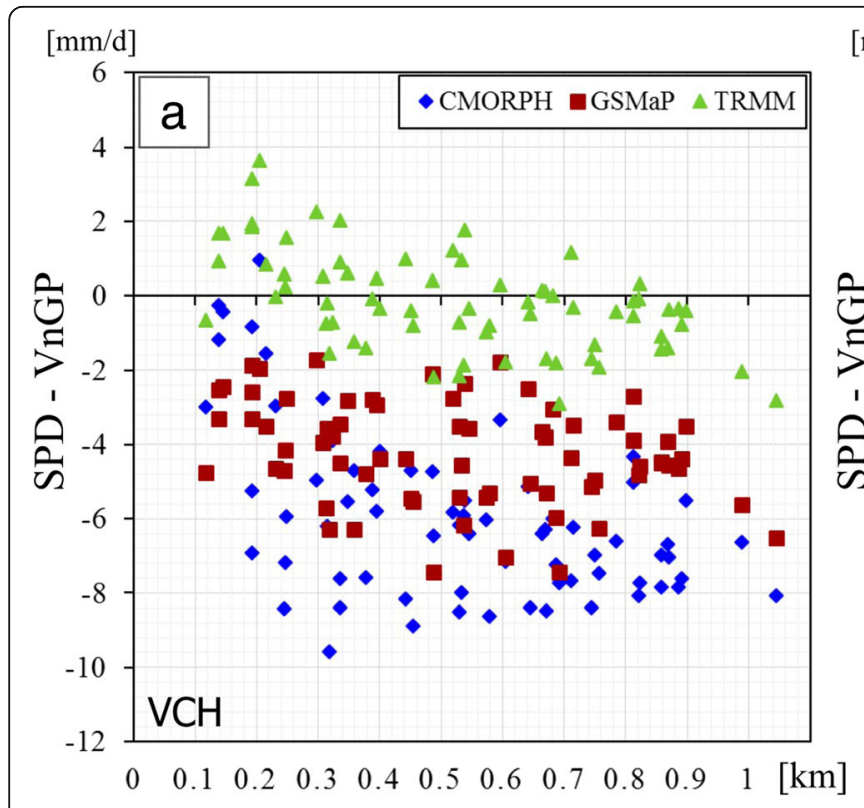

Elevation

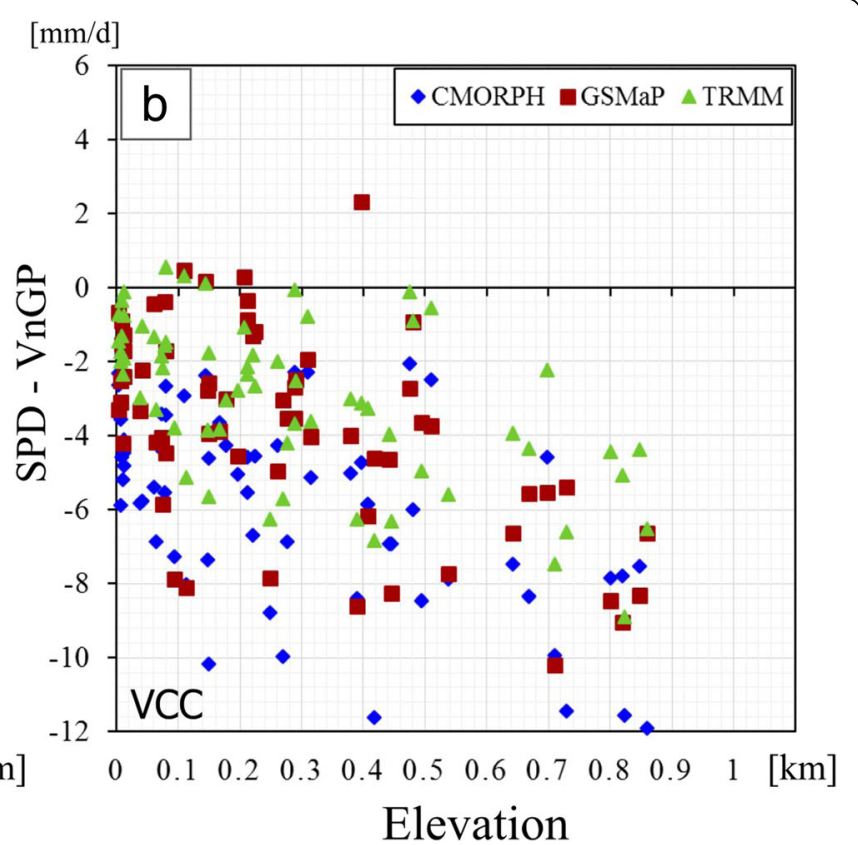

Elevation

Fig. 13 Scatter plots for grid point averaged elevation (abscissa, unit km) and the time-averaged rainfall bias (SPDs rainfall minus VnGP rainfall; ordinate, unit $\mathrm{mm}_{\mathrm{day}}{ }^{-1}$ ) for a MJJA over the VCH and $\mathbf{b}$ SOND over the VCC in 2001-2010 
could be attributed to the southwest monsoon, while in the VCC, precipitation is caused by several factors, such as the impacts of the NM and TI and/or the interactions between them. Therefore, the relationship between the $U$ component and $\triangle P$ in the $\mathrm{VCH}$ is more significant than that in the VCC.

In addition, to evaluate the relationship between the time-averaged rainfall bias $(\Delta P)$ at each grid and the elevation over these regions, the mean elevation of each grid was obtained from the GTOPO30 data. Overall, $|\Delta P|$ tends to increase as the elevation increases (Fig. 13). A similar relationship between elevation and the accuracy of the SPDs has also been observed in previous studies, and this is mainly attributed to the fact that retrieval algorithms based on infrared imagery have problems associated with the detection of warm orographic rainfall (Kidd 2001; Dinku et al. 2008; Toté et al. 2015). The $\mathrm{CMORPH}$ estimation is largely based on the thermal infrared band (Joyce et al. 2004), thus the CMORPH algorithm can misinterpret warm clouds in elevated topography, such as that in the VCH (Fig. 13a). In the case of the VCC, CMORPH and GSMaP clearly present slopes similar to those from TRMM, but with different biases (Fig. 13b). These results indicate that other SPDs could potentially be improved in high-elevation areas by using the correction methods proposed by Yin et al. (2008) and Shige et al. (2013).

\section{Conclusions}

In this study, three SPDs (CMORPH, GSMaP, and TRMM) were assessed by comparison with VnGP during rainy seasons in 2001-2010 over Central Vietnam. In addition to evaluations based on spatial (grid and region) and temporal (daily and monthly) scales, the ability of SPDs to detect the heavy rainfall in WHR days caused by TI and NM in the VCC region was also considered.

The results obtained demonstrate that, in complex topographic regions such as Central Vietnam, estimation algorithms combined with multi-sensors and rain gauge observation or data reanalysis-based correction processes lead to different performances. In general, the SPDs studied generate reasonable estimates of precipitation in the plains but exhibit slightly poorer performance for higherelevation areas. TRMM exhibits superior performance (in terms of higher correlations, lower biases, and lower RMSE ratios) than GSMaP and CMORPH for the $\mathrm{VCH}$, specifically at regional and monthly scales. GSMaP exhibits moderately good performance for the $\mathrm{VCH}$ but is less efficient for the VCC. Conversely, CMORPH performs better for the VCC than for the $\mathrm{VCH}$.

The three SPDs perform better in detecting heavy rainfall on the WHR days in TI cases than in NM cases. In general, TRMM presents lower RMSE ratios and higher POD and HSS values than GSMaP and
CMORPH for most thresholds. Therefore, TRMM is deemed to be reliable and, thus, shows potential for use in hydrological applications. This conclusion is consistent with those of other studies (Hobouchian et al. 2017; Mantas et al. 2015) conducted in different areas, which demonstrated the advantages of gauge calibration and multi-satellite passive microwave data incorporation. Hydrological applications considered in further studies should take into account these potential suggestions.

Finally, the SPDs underestimate rainfall depending on zonal wind speed and elevation, but the CMORPH and GSMaP biases are larger than those of TRMM. Therefore, variability in elevation plays an important role in these biases and suggests that CMORPH and GSMaP can be further improved via algorithm correction for elevation and zonal wind speed.

\section{Abbreviations}

CMORPH: Climate Prediction Center Morphing; CORR: Correlation coefficient; CPC: Climate Prediction Center; FAR: False alarm ratio; GPCC: Global Precipitation Climatology Centre; GSMaP: Global Satellite Mapping of Precipitation; HSS: Heidke skill score; ITCZ: Inter-tropical Convergence Zone; MJJA: May to August; NHMS: National Hydro-Meteorology Service of Vietnam; NM: Northeast Winter Monsoon; POD: Probability of detection; RMSE ratio: Root mean square error ratio; SOND: September to December; SPDs: Satellite Precipitation Datasets; TC: Tropical cyclone; TI: TCs and ITCZ; TRMM: Tropical Rainfall Measuring Mission; VCC: Vietnam Central Coast; VCH: Vietnam Central Highlands; VnGP: Vietnam Gridded Precipitation; WHR: Widespread heavy rainfall

\section{Acknowledgements}

We would like to acknowledge the constructive comments of the editor and the three anonymous reviewers. The authors also acknowledge Dr. Phu Nguyen, University of California Irvine, for his contributions and comments to improve the manuscript. This research was supported by the Japan Aerospace Exploration Agency (JAXA) Precipitation Measuring Mission and the Vietnam National Foundation for Science and Technology Development (NAFOSTED) under Grant 105.06-2018.05. We would like to thank the National Hydro-Meteorological Service of Vietnam (NHMS) for providing station data. The GSMaP products were produced and distributed by the Earth Observation Research Center, JAXA. The CMORPH data were sourced from NOAA/CPC from their website at ftp://ftp.cpc.ncep.noaa.gov/precip/ CMORPH_V1.0/, while the TRMM data were sourced from NASA/JAXA from https://disc.gsfc.nasa.gov/mirador-guide?keyword=TRMM_3B42, the ERAInterim Reanalysis data were obtained from ECMWF at http://apps.ecmwfint/ datasets/, and the GTOPO30 were obtained from EROS Data Center at https://earthexplorer.usgs.gov/.

\section{Authors' contributions}

$L T T, J M$, and TND conceived the topic. LTT carried out the analysis and conducted major parts of the study. All authors discussed the results and commented on the manuscript. All authors read and approved the final manuscript.

\section{Authors' information}

LTT is currently a researcher at the University of Science and Technology of Hanoi, in the REMOSAT laboratory, Department of Space and Applications. This study was mainly conducted when LTT was a Ph.D. student at the Tokyo Metropolitan University, Japan, in the Department of Geography, Laboratory of Climatology. JM is the director of the Research Center for Climatology, a professor in the Department of Geography at the Tokyo Metropolitan University, and a visiting principal scientist at the Japan Agency for Marine-Earth Science and Technology. TND is an associate professor in the Department of Space and Applications at the University of Science and 
Technology of Hanoi. MIN is a research fellow at the Tokyo Metropolitan University. Tl is a project assistant professor at the Tokyo Metropolitan University.

\section{Funding}

$L T T$, JM, TND, and MIN were supported by the 8th JAXA PMM Project (JXPSPC-436541, PI No. 204). LTT and JM were also supported by the Tokyo Human Resources Fund for City Diplomacy of Tokyo Metropolitan University received from the Tokyo Metropolitan Government. JM and TI were additionally supported by the JSPS KAKENHI grant number 26220202. TND was supported by the Vietnam National Foundation for Science and Technology Development (NAFOSTED) under grant 105.06-2018.05.

\section{Availability of data and materials}

The datasets analyzed in the current study are available from the corresponding author on request.

\section{Competing interests}

The authors declare that they have no competing interests.

\section{Author details}

'Department of Geography, Tokyo Metropolitan University, 1-1 Minami-Osawa, Hachioji-Shi, Tokyo 192-0397, Japan. ${ }^{2}$ REMOSAT Laboratory, University of Science and Technology of Hanoi (USTH), Vietnam Academy of Science and Technology (VAST), Hanoi, Vietnam. ${ }^{3}$ Dynamic Coupling of Ocean-Atmosphere-Land Research Program, Japan Agency for Marine-Earth Science and Technology, Yokosuka, Kanagawa 237-0061, Japan.

\section{Received: 4 July 2017 Accepted: 5 July 2019}

\section{Published online: 31 July 2019}

\section{References}

Chen TC, Tsay JD, Yen MC, Matsumoto J (2012a) Interannual variation of the late fall rainfall in Central Vietnam. J Clim 25:392-413. https://doi.org/10.1175/ JCLI-D-11-00068.1

Chen TC, Yen MC, Tsay JD, Alpert J, Tan Thanh NT (2012b) Forecast advisory for the late fall heavy rainfall/flood event in Central Vietnam developed from diagnostic analysis. Wea Forecasting 27:1155-1177. https://doi.org/10.1175/ WAF-D-11-00104.1

Dee DP, Uppala SM, Simmons AJ, Berrisford P, Poli P, Kobayashi S, Andrae U, Balmaseda MA, Balsamo G, Bauer P, Bechtold P, Beljaars ACM, van de Berg L, Bidlot J, Bormann N, Delsol C, Dragani R, Fuentes M, Geer AJ, Haimberger L, Healy SB, Hersbach H, Hólm EV, Isaksen L, Kållberg P, Köhler M, Matricardi M, McNally AP, Monge BM, Morcrette JJ, Park BK, Peubey C, Rosnay P, Tavolato C, Thépaut JN, Vitart F (2011) The ERA-interim reanalysis: configuration and performance of the data assimilation system. Quar J Royal Meteorol Soc 137: 553-597. https://doi.org/10.1002/qj.828

Dinku T, Ceccato P, Grover-Kopec E, Lemma M, Connor SJ, Ropelewski CF (2008) Validation of satellite rainfall products over East Africa's complex topography. Int J Remote Sensing 28:1503-1526. https://doi.org/10.1080/01431160600954688

Dinku T, Ruiz F, Connor SJ, Ceccato P (2010) Validation and intercomparison of satellite rainfall estimates over Colombia. J Appl Meteorol Climatol 49:10041014. https://doi.org/10.1175/2009JAMC2260.1

Gao YC, Liu M (2013) Evaluation of high-resolution satellite precipitation products using rain gauge observations over the Tibetan Plateau. Hydrol Earth Syst Sci 17:837. https://doi.org/10.5194/hess-17-837-2013

Hobouchian MP, Salio P, Skabar YG, Vila D, Garreaud R (2017) Assessment of satellite precipitation estimates over the slopes of the subtropical Andes. Atmos Res 190:43-54. https://doi.org/10.1016/j.atmosres.2017.02.006

Huffman GJ, Bolvin DT (2013) TRMM and other data precipitation data set documentation. NASA, Greenbelt, pp 1-40 Available online at https://pmm. nasa.gov/sites/default/files/document_files/3B42_3B43_doc_V7.pdf

Jamandre CA, Narisma GT (2013) Spatio-temporal validation of satellite-based rainfall estimates in the Philippines. Atmos Res 122:599-608. https://doi.org/1 0.1016/j.atmosres.2012.06.024

Joyce RJ, Janowiak JE, Arkin PA, Xie P (2004) CMORPH: a method that produces global precipitation estimates from passive microwave and infrared data at high spatial and temporal resolution. J Hydrometeorol 5:487-503. https://doi. org/10.1175/1525-754

Kidd C (2001) Satellite rainfall climatology: a review. Int J Climatol 21:1041-1066. https://doi.org/10.1002/joc.635
Kobayashi S, Yukinari OTA, Harada Y, Ebita A, Moriya M, Onoda H, Onogi K, Kamahori H, Kobayashi C, Miyaoka K, Takahashi K (2015) The JRA-55 reanalysis: general specifications and basic characteristics. J Met Soc Japan 93:5-48. https://doi.org/10.2151/jmsj.2015-001

Kubota T, Ushio T, Shige S, Kida S, Kachi M, Okamoto KI (2009) Verification of high-resolution satellite-based rainfall estimates around Japan using a gaugecalibrated ground-radar dataset. J Met Soc Japan 87A:203-222. https://doi. org/10.2151/jmsj.87A.203

Mantas VM, Liu Z, Caro C, Pereira AJSC (2015) Validation of TRMM multi-satellite precipitation analysis (TMPA) products in the Peruvian Andes. Atmos Res 163 : 132-145. https://doi.org/10.1016/j.atmosres.2014.11.012

Matsumoto J (1997) Seasonal transition of summer rainy season over Indochina and adjacent monsoon region. Adv Atmos Sci 14:231-245. https://doi.org/1 0.1007/s00376-997-0022-0

Ngo-Duc T, Matsumoto J, Kamimera H, Bui HH (2013) Monthly adjustment of Global Satellite Mapping of Precipitation (GSMaP) data over the VuGiaThuBon River Basin in Central Vietnam using an artificial neural network. Hydrol Res Lett 7:85-90. https://doi.org/10.3178/hrl.7.85

Ngo-Thanh H, Ngo-Duc T, Nguyen-Hong H, Baker P, Phan-Van T (2017) A distinction between rainy season and summer season over the Central Highlands of Vietnam. Theor Appl Climatol. https://doi.org/10.1007/s00704-017-2178-6

Nguyen DQ, Renwick J, McGregor J (2014) Variations of surface temperature and rainfall in Vietnam from 1971 to 2010. Int J Climatol 34:249-264. https://doi. org/10.1002/joc.3684

Nguyen-Le D, Matsumoto J, Ngo-Duc T (2015) Onset of the rainy seasons in the eastern Indochina Peninsula. J Clim 28:5645-5666. https://doi.org/10.1175/ JCLI-D-14-00373.1

Nguyen-Thi HA, Matsumoto J, Ngo-Duc T, Endo N (2012) A climatological study of tropical cyclone rainfall in Vietnam. SOLA 8:41-44. https://doi.org/10.2151/ sola.2012-011

Nguyen-Xuan T, Ngo-Duc T, Kamimera H, Trinh-Tuan L, Matsumoto J, Inoue T, PhanVan T (2016) The Vietnam gridded precipitation (VnGP) dataset: construction and validation. SOLA 12:291-296. https://doi.org/10.2151/sola.2016-057

NHMS (2017) Annual Reports of Hydro-Meteorological Characteristics. http:// kttvqg.gov.vn. Accessed 1 Jan 2017. (in Vietnamese)

Nugent AD, Smith RB, Minder JR (2014) Wind speed control of tropical orographic convection. J Atmos Sci 71:2695-2712. https://doi.org/10.1175/ JAS-D-13-0399.1

Phan VT, Ngo-Duc T (2009) Seasonal and interannual variations of surface climate elements over Vietnam. Clim Res 40:49-60. https://doi.org/10.3354/cr00824

Schneider U, Becker A, Finger P, Meyer-Christoffer A, Ziese M, Rudolf B (2014) GPCC's new land surface precipitation climatology based on qualitycontrolled in situ data and its role in quantifying the global water cycle. Theor Appl Climatol 115:15-40. https://doi.org/10.1007/s00704-013-0860-X

Shen Y, Xiong A, Wang Y, Xie P (2010) Performance of high resolution satellite precipitation products over China. J Geophys Res Atmos 115(D2). https://doi. org/10.1029/2009JD012097

Shige S, Kida S, Ashiwake H, Kubota T, Aonashi K (2013) Improvement of TMI rain retrievals in mountainous areas. J Appl Meteorol Climatol 52:242-254. https:// doi.org/10.1175/JAMC-D-12-074.1

Shige S, Kummerow CD (2016) Precipitation-Top Heights of heavy orographic rainfall in the Asian monsoon region. J Atmos Sci 73:3009-3024. https://doi. org/10.1175/JAS-D-15-0271.1

Takahashi HG (2013) Orographic low-level clouds of Southeast Asia during the cold surges of the winter monsoon. Atmos Res 131:22-33. https://doi.org/1 0.1016/j.atmosres.2012.07.005

Tang L, Tian Y, Yan F, Habib E (2015) An improved procedure for the validation of satellite-based precipitation estimates. Atmos Res 163:61-73. https://doi. org/10.1016/j.atmosres.2014.12.016

Tapiador FJ, Turk FJ, Petersen W, Hou AY, García-Ortega E, Machado LA, Angelis CF, Salio P, Kidd C, Huffman GJ, De Castro M (2012) Global precipitation measurement: methods, datasets and applications. Atmos Res 104:70-97. https://doi.org/10.1016/j.atmosres.2011.10.021

Thiemig V, Rojas R, Zambrano-Bigiarini M, Levizzani V, De Roo A (2012) Validation of satellite-based precipitation products over sparsely gauged African river basins. J Hydrometeorol 13:1760-1783. https://doi.org/10.11 75/JHM-D-12-032.1

Toté C, Patricio D, Boogaard H, van der Wijngaart R, Tarnavsky E, Funk C (2015) Evaluation of satellite rainfall estimates for drought and flood monitoring in Mozambique. Remote Sens 7:1758-1776. https://doi.org/1 $0.3390 /$ rs 70201758 
Ushio T, Sasashige K, Kubota T, Shige S, Okamoto Kl, Aonashi K, Inoue T, Takahashi N, Iquchi T, Kachi M, Oki R (2009) A Kalman filter approach to the Global Satellite Mapping of Precipitation (GSMaP) from combined passive microwave and infrared radiometric data. J Met Soc Japan 87A:137-151. https://doi.org/10.2151/jmsj.87A.137

Vernimmen RRE, Hooijer A, Aldrian E, van Dijk AIJM (2012) Evaluation and bias correction of satellite rainfall data for drought monitoring in Indonesia. Hydrol Earth Syst Sci 16:133-146. https://doi.org/10.5194/hess-16-133-2012

Willmott CJ, Rowe CM, Philpot WD (1985) Small-scale climate maps: a sensitivity analysis of some common assumptions associated with grid-point interpolation and contouring. Amer Cartogr 12:5-16. https://doi.org/10.155 9/152304085783914686

Xie P, Chen M, Yang S, Yatagai A, Hayasaka T, Fukushima Y, Liu C (2007) A gaugebased analysis of daily precipitation over East Asia. J Hydrometeorol 8:607626. https://doi.org/10.1175/JHM583.1

Xie P, Joyce R, Wu S, Yoo SH, Yarosh Y, Sun F, Lin R (2017) Reprocessed, biascorrected CMORPH global high-resolution precipitation estimates from 1998. J Hydrometeorol. https://doi.org/10.1175/JHM-D-16-0168.1

Yamamoto MK, Shige S (2015) Implementation of an orographic/ nonorographic rainfall classification scheme in the GSMaP algorithm for microwave radiometers. Atmos Res 163:36-47. https://doi.org/10.1016/j. atmosres.2014.07.024

Yen MC, Chen TC, Hu HL, Tzeng RY, Dinh DT, Nguyen TTT, Wong CJ (2011) Interannual variation of the fall rainfall in Central Vietnam. J Met Soc Japan 89A:259-270. https://doi.org/10.2151/jmsj.2011-A16

Yin ZY, Zhang X, Liu X, Colella M, Chen X (2008) An assessment of the biases of satellite rainfall estimates over the Tibetan Plateau and correction methods based on topographic analysis. J Hydrometeorol 9:301-326. https://doi.org/1 $0.1175 / 2007$ JHM903.1

Yokoi S, Matsumoto J (2008) Collaborative effects of cold surge and tropical depression-type disturbance on heavy rainfall in Central Vietnam. Mon Wea Rev 136:3275-3287. https://doi.org/10.1175/2008MWR2456.1

\section{Publisher's Note}

Springer Nature remains neutral with regard to jurisdictional claims in published maps and institutional affiliations.

\section{Submit your manuscript to a SpringerOpen ${ }^{\circ}$ journal and benefit from:}

- Convenient online submission

- Rigorous peer review

- Open access: articles freely available online

High visibility within the field

- Retaining the copyright to your article

Submit your next manuscript at $\boldsymbol{\nabla}$ springeropen.com 